\title{
The Explanation of Differences in Regional Carbon Emissions in China
}

\author{
Yuting He \\ School of Economics and Management \\ Shenyang Ligong University \\ Shenyang, Liaoning, P. R. China. \\ hyt1975@163.com
}

\author{
Tianbai Xia \\ School of Economics and Management \\ Shenyang Ligong University \\ Shenyang, Liaoning, P. R. China. \\ xtb621@163.com
}

\begin{abstract}
This paper attempts to analyze the factors affecting the carbon emissions in China, and the central, eastern and western regions of this country respectively, by building models of carbon emission affecting factors and using inter-provincial panel data from 2005 to 2009. This research shows that the carbon emissions and GDP per capita have a relationship of an inverted U-shaped environmental Kuznets curve in China and the eastern region of the country. In reference to the relationship between the unit GDP energy consumption and carbon emissions, this paper also finds the evidence for the existence of $U$-shaped curves in China and the western region of the country. The increase of technology market turnover contributes to the decrease of carbon emissions in the whole country and western region. But this trend is not obvious in the eastern and central regions. Meanwhile, this paper checks and analyzes the inverted $U$-shaped curve relation mentioned above statistically by means of $\beta$ Convergence Models.
\end{abstract}

Keywords- carbon emissions; affecting factors; differences

\section{INTRODUCTION}

With the significant economy growth, the issues of resource consumption and increase of carbon emissions have been emerging in China (Zou, 2010). The Energy Report of China (2008) points out that carbon emissions in China present in both the increase of total amount of emissions and the regional change of emissions, which can be explained by the uneven distribution of energy resources and economic development in China. The level of economic development, the industrial structure and the energy intensity also affect regional carbon emissions, which reflect different characteristics. The discrepancies on China's regional carbon emissions lie in three aspects at least. First, the distribution of regional carbon emissions is different. Second, regional discrepancies are widening. Third, the elastic coefficients of carbon emission affecting factors in different regions vary greatly with different reactions of regional carbon emissions to their affecting factors. As to the interpretation of discrepancies on China's regional carbon emissions, there are many researches done by $\mathrm{Xu}$ (2006), Zhang (2006), Du (2007), Tan (2008), Zhu (2009), Guo (2009), etc. However, this paper differs from these researches in two main aspects. On one hand, many of the current literatures manage to calculate the regression coefficient of national overall carbon emission affecting factors (such as Zhao, 2009; Li, 2010). Nevertheless, they ignore the impacts of different regions on carbon emissions; as a result, the explanations to discrepancies of regional emissions may be insufficient. For this reason, this paper tries to establish a regression equation between regional carbon emissions and their affecting factors in order to span the gap of current researches. On the other hand, parts of the present literatures tend to convey the direct-viewing contrast of carbon emissions of each province, lacking an analysis of the trend for discrepancies on China's regional carbon emissions. Accordingly, this paper attempts to make a quantitative analysis of the trend of discrepancies on China's regional carbon emissions by using $\beta$ Convergence Models on the basis of establishing a regression equation between carbon emissions and their affecting factors.

\section{ESTIMATION OF MODELS OF CARBON EMISSIONS BASED ON PANEL DATA}

\section{A. Data,Variables and the Setting of Econometric Model}

Taking the availability of data into consideration, this paper selects empirical data in a time span between 2005 and 2009. For lack of the data from Tibet, Hong Kong and Macau, this paper selects 30 areas (provinces, autonomous regions, and municipalities). According to the Statistical Yearbook of China, this paper divides China into three parts: the eastern region, the central region and the western region. The data come from every year's Industry Statistical Yearbook of China, Energy Statistical Yearbook of China and some statistical reports. Explanation to the main variables as follows:

(1) Explained variable: in this paper, carbon emission (CE) is the explained variable.

(2) Explaining variable: (1) the level of economic development: in this paper, the level of economic development is measured according to GDP per capita (PGDP), namely, the ration of the total output and total population, which is often used for this purpose. (2) the level of energy consumption: in this paper, the level of energy consumption is measured by the unit GDP energy consumption (UC) (ton of SCE/10 000 yuan) and the industrial added value of unit energy consumption (IC) (ton of SCE/10 000 yuan). The unit GDP energy consumption is a major index to reflect the level of energy consumption and the status of energy conservation and consumption reduction, which refers to the ratio of the total primary energy supply and gross domestic product (GDP). It is an index of energy utilizing efficiency. This index can also indicate the energy utilization degree in a country's economic activities, reflecting the 
economic structure and the change of energy utilizing efficiency. The industrial added value of unit energy consumption is the ratio between the industrial energy consumption and industrial added value, which is an index representing the change of industrial energy utilizing efficiency (3) the level of technology: in this paper, the level of technology is measured by technology market turnover (TP) (0.1billion). This index reflects the impact on carbon emission level from the traditional energy use upgraded by new technology.

Table I shows 30 areas annual mean value and standard deviation of the main variables.

This paper introduces China's inter-provincial panel data into the following regression equation:

$$
C E=\beta+\sum \alpha_{i} \gamma_{i}+\omega
$$

$\mathrm{CE}$ represents the value of carbon emission (explained variable). ${ }^{\gamma_{i}}$ represents the factors which affect the value of carbon emission (explaining variable). $\alpha_{i}$ is the estimated parameter. $\omega$ is the standard white noise. $\beta$ is the intercept item. The explaining variables include: the unit GDP energy consumption (UC), constant price GDP per capita (PGDP), the industrial added value of unit energy consumption (IC), technology market turnover (TP). The square of PGDP (PGDPS), the square of IC (ICS) and the square of unit GDP energy consumption (UCS) are also included in the regression equation to calculate the quadratic relationship between carbon emissions and these variables.

\section{B. Correlation Analysis}

Table II shows correlation coefficients between variables. According to the table, it can be seen that correlation coefficients between $\mathrm{CE}$ and other variables mentioned above are less than 0.3. The correlation coefficients between PGDP, IC and TP reach more than 50\%, showing the statistical significance. Meanwhile, this paper further investigates the variance inflation factors and finds that they are all less than 10. So the multicollinearity problem is not severe. From the samples in this research, it can be found that the high IC and UC will bring down the level of GDP per capita. In terms of low-carbon economy characteristic, the carbon emission can be reduced through the innovation and upgrading of technology to promote the upgrading of traditional heavy chemical industries. It is improper to eliminate these traditional industries completely.

TABLE II. CORRELATION COEFFICIENTS BETWEEN VARIABLES

\begin{tabular}{c|c|c|c|c|c}
\hline & CE & PGDP & UC & IC & TP \\
\hline CE & 1 & & & & \\
\hline PGDP & 0.1395 & 1 & & & \\
\hline $\mathbf{U C}$ & -0.1830 & $-0.4577^{*}$ & 1 & & \\
\hline IC & -0.1220 & $-0.5414^{*}$ & $0.8995^{*}$ & 1 & \\
\hline TP & -0.0626 & $0.7210^{*}$ & -0.3421 & $-0.3714^{*}$ & 1 \\
\hline
\end{tabular}

\section{Regression results and Explanations}

Table III provides the regression results of the carbon emission affecting factors in the whole country, eastern region, central region and western region under the fixed effect and random effect. Hausmann Test indicates that the regression analysis of each region should choose a fixed effect model.

TABLE I. STATISTICAL DESCRIPTION OF EACH VARIABLE

\begin{tabular}{c|c|c|c|c|c|c}
\hline Variable & $\begin{array}{c}\text { Observed } \\
\text { value }\end{array}$ & $\begin{array}{c}\text { Mean } \\
\text { value }\end{array}$ & Median & Maximum & Minimum \\
\hline CE & 150 & 2.255 & 1.749 & 6.660 & 2.460 \\
deviation
\end{tabular}


TABLE III. REGRESSION RESUlts BETWEEN REGIONAL CARBON EMISSIONS AND THEIR AFFECTING FACTORS

\begin{tabular}{|c|c|c|c|c|c|c|c|c|}
\hline \multicolumn{2}{|l|}{ Variable } & \multicolumn{2}{|c|}{ Nationwide } & \multicolumn{2}{|c|}{ Eastern region } & Central region & \multicolumn{2}{|c|}{ Western region } \\
\hline $\begin{array}{l}\text { Method of } \\
\text { estimation }\end{array}$ & $\mathrm{FE}$ & $\mathrm{RE}$ & FE & $\mathrm{RE}$ & $\mathrm{FE}$ & $\mathrm{RE}$ & $\mathrm{FE}$ & $\mathrm{RE}$ \\
\hline$\beta$ & $4.4880^{*}$ & $3.2107^{*}$ & 0.1846 & -0.5068 & 5.8415 & $-6.2623^{*}$ & $6.2934^{*}$ & $1.0373^{*}$ \\
\hline PGDP & $0.4442^{*}$ & $0.4804^{*}$ & $0.4113^{ \pm}$ & $0.4336^{ \pm}$ & -1.5789 & $2.7977^{*}$ & 0.0242 & $-0.5444^{*}$ \\
\hline PGDPS & $-0.0341^{*}$ & $-0.0366^{*}$ & $-0.0357^{ \pm}$ & $-0.0366^{ \pm}$ & 0.5502 & -0.2711 & $0.0816^{* *}$ & $0.2906^{*}$ \\
\hline $\mathrm{UC}$ & $-3.5559^{*}$ & $-2.2235^{* *}$ & 1.9785 & 3.0378 & -4.8744 & $5.2468^{*}$ & $-3.7510^{*}$ & 0.4532 \\
\hline UCS & $0.7081^{*}$ & $0.4778^{*}$ & -0.8583 & -1.0972 & 1.4473 & $-2.2954^{*}$ & $0.6254^{*}$ & $-0.2496^{*}$ \\
\hline IC & 0.3881 & 0.2794 & 0.4760 & 0.3207 & 1.0893 & 0.4132 & 0.0750 & 0.1533 \\
\hline ICS & $-0.0561^{* *}$ & $-0.0403^{ \pm}$ & -0.0111 & 0.0095 & $-0.1870^{ \pm}$ & $0.2126^{*}$ & -0.0235 & 0.0157 \\
\hline $\mathrm{TP}$ & $-0.0009^{ \pm}$ & $-0.0010^{* *}$ & -0.0005 & -0.0005 & -0.0065 & $-0.0084^{* *}$ & $-0.0088^{*}$ & -0.0012 \\
\hline$R^{2}$ & 0.9836 & 0.6593 & 0.9865 & 0.6809 & 0.9558 & 0.6779 & 0.9913 & 0.5195 \\
\hline $\begin{array}{l}\text { Inflection } \\
\text { Point } \\
\text { (PGDP) }\end{array}$ & 6.5132 & 6.5628 & 5.7605 & 5.9235 & 1.4348 & 5.1599 & - & 0.9367 \\
\hline $\begin{array}{l}\text { Inflection } \\
\text { Point (UC) }\end{array}$ & 2.5109 & 2.3268 & 1.1526 & 1.3843 & 1.6840 & 1.1429 & 2.9989 & 0.9079 \\
\hline $\begin{array}{l}\text { Inflection } \\
\text { Point (IC) }\end{array}$ & 3.4590 & 3.4665 & 21.4414 & - & 2.9126 & - & 1.5957 & - \\
\hline $\mathrm{D}-\mathrm{W}$ & 0.7741 & 0.5575 & 0.6453 & 0.5311 & 1.1850 & 0.5832 & 2.2357 & 0.5690 \\
\hline F-statistic & 224.7985 & 27.2081 & 203.6665 & 13.4159 & 47.8660 & 8.4632 & 266.119 & 5.3250 \\
\hline Hausmann & & 19.2753 & & 3.8182 & & 183.0746 & & 429.157 \\
\hline $\begin{array}{l}\text { Observed } \\
\text { data }\end{array}$ & 150 & & 65 & & 40 & & 45 & \\
\hline
\end{tabular}

table iv. $\quad$ Estimation Results of Carbon Emissions in the Absolute $\beta$ Convergence Model

\begin{tabular}{|c|c|c|c|c|}
\hline $\begin{array}{l}\text { The Estimated } \\
\text { Parameters }\end{array}$ & Nationwide & Eastern region & Central region & Western region \\
\hline Intercept $\alpha$ & $0.0727^{a}$ & $0.0690^{a}$ & $0.0487^{b}$ & $0.0787^{a}$ \\
\hline$\lambda$ & 0.0065 & 0.0073 & -0.0315 & 0.0061 \\
\hline$\beta$ & $-0.0064^{d}$ & $-0.0072^{d}$ & $0.0341^{d}$ & -0.0060 \\
\hline$R^{2}$ & 0.0338 & 0.0935 & 0.2305 & -0.0897 \\
\hline DW Values & 1.6371 & 1.6484 & 1.0448 & 3.2586 \\
\hline F Values & 2.0143 & 2.2378 & 3.0970 & 0.3417 \\
\hline
\end{tabular}

Note : ${ }^{a}$ represents a statistical significance over $1 \% ; \quad$ represents a statistical significance over $5 \%$; ${ }^{b}$ represents a statistical significance over $10 \%$; represents a statistical significance over $20 \%$.

represents a statistical significance over $5 \% ;{ }^{ \pm}$represents a statistical significance over $10 \%$.

Considering the country as a whole, all the parameters have statistical significances except the variables of IC. GDP per capita is positively correlated with $\mathrm{CE}$ and the parameter of the square of GDP per capita is negative, which illustrates that CE and GDP per capita have a relationship of an inverted U-shaped curve. The inflection point is about 65,132 yuan.

Therefore, once the nationwide GDP per capita reaches the inflection point, the growth in carbon emissions could be slowed. It reflects the Chase Effect of some backward areas in China. In contrast, UC is negatively correlated with CE and the parameter of UCS is positive, which means that UC and CE have a U-shaped curve relationship. The inflection point is about 2.5109 ton of SCE/10 000 yuan. So, once the nationwide UC surpasses this inflection point, the rising of carbon emissions will be accelerating. The results also indicate that TP is negatively correlated with $\mathrm{CE}$, showing that the increase of TP contributes to the decrease of CE.

In the eastern region, GDP per capita is positively correlated with $\mathrm{CE}$ and the parameter of the square of GDP per capita is negative. Thus it illustrates that CE and GDP per capita have a relationship of an inverted U-shaped curve. The inflection point is about 57,605 yuan. Therefore, once GDP per 
capita in the eastern region reaches the inflection point, the growth in carbon emissions could be slowed.

In the central region, all the parameters of variables have no statistic significances. Therefore, it is difficult to identify the inflection point. This also means that each variable has no noticeable impact on CE.

In the western region, $\mathrm{UC}$ is negatively correlated with $\mathrm{CE}$ and the parameter of UCS is positive, which means that UC and $\mathrm{CE}$ have a U-shaped curve relationship. The inflection point is around 2.9989 ton of SCE/10 000 yuan. So, once UC in the western region surpasses this inflection point, the rising of carbon emission will be accelerating. In addition, $\mathrm{TP}$ is negatively correlated with $\mathrm{CE}$. This result suggests that the increase of TP contributes to the decrease of CE.

\section{THE CONVERGENCY TENDENCY ANALYSIS OF CARBON EMISSIONS IN REGIONS}

\section{A. Absolute ${ }^{\beta}$ Convergence Model}

The following is the general regression model for absolute $\beta$

convergence of carbon emissions in each region in this

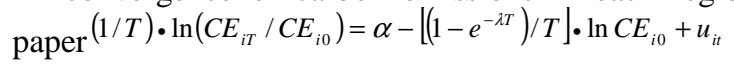

$$
C E_{i t}=(1 / T) \cdot \ln \left(C E_{i T} / C E_{i 0}\right), \quad \text { above } \quad \text { equation: }
$$

In this model, the subscript $i$ represents each region; the subscript $t$ refers to a certain period of time; the subscript 0 means the base year in a certain period of time; $T$ is the final year in a certain period of time; $C E_{i 0}$ refers to carbon emissions in the base year in $\mathrm{i}$ region; $C E_{i T}$ means carbon emissions in the final year in i region; $C E_{i t}$ is the average growth rate of carbon emissions in a certain period of time in i region; $\alpha$ represents intercept; $\lambda$ represents the convergence rate; $\beta$ is the entire coefficient of $\ln C E_{i 0}$ (carbon emissions in the base year); $u_{i t}$ is the mean of error terms in a certain period of time. Based on the 2005-2009 cross-sectional data in 30 areas, this paper estimates carbon emissions in China and the eastern, central and western regions respectively. Estimation results are listed in Table IV by using non-linear least squares method.

According to the absolute $\beta$ convergence theory, when the sign of parameter $\lambda$ in $\ln C E_{i 0}$ (carbon emissions in regions in the base year) is positive, namely, the sign of the entire coefficient $\beta$ is negative, there is an inverse relationship between the initial level of carbon emissions in regions and its growth rates. Thus, there exists the absolute $\beta$ convergence of regional discrepancies of carbon emissions in this period.
When the sign of $\lambda$ is negative, namely, the sign of $\beta$ is positive, there is a positive relationship between the initial level of carbon emissions in regions and its growth rates. Thus, there is an expansion, but no absolute $\beta$ convergence of regional discrepancies of carbon emissions in this period. The table 3.1 shows that, in the central region, the sign of $\lambda$ is negative, namely, the sign of $\beta$ is positive, which indicates that the discrepancies of carbon emissions are to expand and there is no absolute $\beta$ convergence of carbon emissions. The findings are consistent with what is analyzed above that there is no inflection point in the central region. However, in the whole country and eastern region, the sign of $\lambda$ is positive, namely, the sign $\beta$ is negative, which means there is absolute $\beta$ convergence of carbon emissions and the discrepancies of carbon emissions are gradually narrow. Convergence rates of carbon emissions in China and the eastern region are 0.0065 and 0.0073 , respectively. It indicates the rate of convergence in the eastern region is faster than in the whole country, which is consistent with what is analyzed above that the inflection point of GDP per capita in the eastern region is less than that in the whole country. It is noteworthy that the estimation of $\beta$ in the western region has no statistical significance and it cannot be determined that the discrepancies of carbon emissions are to shrink in the region.

\section{B. Conditional $\beta$ Convergence Model}

Three condition variables $X_{i t}, I_{i t}$ and $C_{i t}$ are added to the above absolute $\beta$ convergence model. Thus, the conditional $\beta$ convergence model is as follows:

$$
C E_{i t}=\alpha+\beta \ln C E_{i 0}+\gamma X_{i t}+\delta I_{i t}+\eta C_{i t}+u_{i t}
$$

In this model, $X_{i t}$ is the mean of GDP per capita in i region in a certain period of time; ${ }^{i t}$ is the mean of the unit GDP energy consumption in $i$ region in a certain period of time; ${ }^{C_{i t}}$ refers to the mean of the industrial added value of unit energy consumption in $\mathrm{i}$ region in a certain period of time. Estimation results of the model are listed in Table $\mathrm{V}$. 
TABLE V. ESTIMATION RESULTS OF CARBON EMISSIONS IN THE Conditional $\beta$ Convergence Model

\begin{tabular}{|c|c|c|c|c|}
\hline $\begin{array}{l}\text { The } \\
\text { Estimated } \\
\text { Parameters }\end{array}$ & Nationwide & $\begin{array}{c}\text { Eastern } \\
\text { region }\end{array}$ & $\begin{array}{c}\text { Central } \\
\text { region }\end{array}$ & $\begin{array}{c}\text { Western } \\
\text { region }\end{array}$ \\
\hline${ }_{\text {Intercept }} \alpha$ & $0.0684^{a}$ & $0.0817^{b}$ & 0.0579 & $0.0346^{d}$ \\
\hline$\beta$ & -0.0061 & -0.0046 & 0.0301 & -0.0076 \\
\hline$\gamma$ & -0.0001 & -0.0019 & 0.0071 & $0.0370^{b}$ \\
\hline$\delta$ & -0.0051 & -0.0187 & $-0.0787^{c}$ & 0.0067 \\
\hline$\eta$ & 0.0044 & 0.0064 & $0.0319^{d}$ & -0.0047 \\
\hline$\overline{R^{2}}$ & -0.0409 & -0.1344 & 0.6833 & 0.5809 \\
\hline F Values & 0.7152 & 0.6445 & 4.7762 & 3.7721 \\
\hline DW Values & 1.7550 & 1.4926 & 1.2845 & 2.2462 \\
\hline
\end{tabular}

Note: ${ }^{a}$ represents a statistical significance over $1 \%$; represents a statistical significance over $5 \% ;{ }^{c}$ represents a statistical significance over $10 \% ;{ }^{d}$ represents a statistical significance over $20 \%$.

The results in the table 3.2 show that after three condition variables are added, the estimation results of $\beta$ in various regions have no statistical significances, which indicates that in a short period of time carbon emissions are not dependent on other condition variables which affect convergence of carbon emissions. The convergence of carbon emissions reflects the fundamentals of regional economic developments. That is, the basic conditions have the gradual equalization.

\section{CONCLUSION}

Through the estimation via established models of interregional carbon emission affecting factors in China and the use of 2005-2009 inter-provincial panel data, the results show that there is an inverted U-shape environmental Kuznets curve relationship between carbon emissions and GDP per capita in the whole country and eastern region, and a U-shape curve relationship between the unit GDP energy consumption and carbon emissions in the whole country and western region. Meanwhile, the increase of technology market turnover contributes to the decrease of carbon emissions in the whole country and western region. The estimation results from $\beta$ convergence models indicate that, in the long term, convergence of carbon emissions in various regions may still come down to the absolute $\beta$ convergence.

The revelations of this study include the following three aspects. First, when relevant carbon emission policies are formulated and implemented, the discrepancies of regional economic geography and energy consumption should be taken into consideration thoroughly. To reach the inflection point of carbon emission, it must be done to accelerate regional economic growth, reduce energy consumption intensity, speed up industrial restructuring and develop non-resource-based industries. Second, actively promote the popularization and application of energy conservation and emission reduction technologies and establish the technical service system of energy conservation and emission reduction. Third, in China, the narrowing of the overall discrepancies of the regional carbon emissions has just begun. It has a long way to go to consolidate and develop this trend. It may take a certain time to facilitate the narrowing of the discrepancies of the basic conditions between regions and the equalization.

\section{REFERENCES}

[1] Stefan Waushara. CO2 emission allowance allocation mechanisms, a locative efficiency and the environment: a static and dynamic perspective [J]. Pattern Recognition, 2000.1(33):149-160

[2] Frank Jots. John C. V. Plessey. Optimal intensity targets for greenhouse gas emissions trading under uncertainty $[\mathrm{J}]$. Environmental and Resource Economics, 2007.(38):259-284

[3] Regina Betz - Todd Sanderson - Tahoma Acnes. In or out: efficient inclusion of installations in an emissions trading scheme $[\mathrm{J}]$. Regulatory Economics, 2009.(4):50-53

[4] JOHN C.V. PEZZEY. Emission Taxes and Trade able Permits a Comparison of Views on Long-Run Efficiency [J]. Environmental and Resource Economics, 2003.329-341, 329-342

[5] Karl-Martin Earhart - Christian Hoppe, Ralf Loaches. Environmental and Resource Economics [J]. Abuse of EU Emissions Trading for Tacit Collusion, 2008.(41):347-361 